\title{
O PAPEL DO GESTOR ESCOLAR E DAS POLÍTICAS PÚBLICAS NAS CRECHES
}

\section{ARTIGO ORIGINAL}

SANTOS, Rosenilda de Jesus Couto ${ }^{1}$

SEÁRA, Maxsoelia Souza de Almeida ${ }^{2}$

MONT'ALVERNE, Clara Roseane da Silva Azevedo ${ }^{3}$

SANTOS, Rosenilda de Jesus Couto. SEÁRA, Maxsoelia Souza de Almeida. MONT'ALVERNE, Clara Roseane da Silva Azevedo. 0 papel do gestor escolar e das Políticas Públicas nas creches. Revista Científica Multidisciplinar Núcleo do Conhecimento. Ano 05, Ed. 09, Vol. 01, pp. 47-55. Setembro de 2020. ISSN: 24480959, Link de acesso: https://www.nucleodoconhecimento.com.br/educacao/papeldo-gestor

\section{RESUMO}

Este estudo parte do pressuposto de que as políticas públicas são de suma importância para o bem estar de toda comunidade escolar, já que esta é primordial na vida de todos, dependendo assim, do papel do gestor escolar para que as ações sejam bem executadas. $O$ objetivo principal é analisar a ação do gestor escolar enfatizando

1 Mestranda em Ciências da Educação, Especialização em Gestão Escolar e Educacional, Especialização em Psicopedagogia, Licenciatura em Pedagogia.

2 Mestranda em Ciências da Especialização em Gestão Escolar e Educacional, Licenciatura em Pedagogia.

${ }^{3}$ Doutorado em Ciência da Educação. Mestrado em Serviço Social. Especialização em Educação na Perspectiva do Ensino Estruturado para Autistas. Especialização em Administração Escolar. Especialização em Especialização Em Ensino Superior. Graduação em Licenciatura Plena em Pedagogia. 
seu desempenho frente aos desafios propostos, em decorrência da implementação de políticas públicas educacionais nas creches. Para que o papel do gestor se concretize, se faz necessário apoderar das determinações legais orientados nos documentos das políticas públicas de educação, onde constam princípios importantes que nortearão a prática do gestor como líder e mentor principal no direcionamento das ações na instituição escolar, frente aos desafios enfrentados do seu oficio. Tendo em vista, que no contexto histórico das creches, as demandas são por uma educação infantil de qualidade que seja capaz de desenvolver ações e promover a formação integral do indivíduo respeitando suas peculiaridades, onde todos estejam envolvidos, tendo o gestor como condutor, organizador e articulador de toda evolução escolar. Portanto, o rumo desta pesquisa é de cunho bibliográfico e documental, bibliográfico porque há uma necessidade de entender todo o processo de gestão educacional e os seus elementos, documental para entender como se dá articulação entre o trabalho do gestor escolar, sua interação com a comunidade escolar e as Políticas Públicas educacionais voltadas para a Educação Infantil. Após esse estudo fica evidente que uma política pública bem executada pelo gestor escolar contribui para o desenvolvimento de uma educação infantil de qualidade, favorecendo o aspecto do cuidar, educar e interagir como pilares indispensáveis para o bom desenvolvimento da criança.

Palavras-chaves: Educação Infantil, Gestão Escolar, Políticas Públicas.

\section{INTRODUÇÃO}

A Educação Infantil, de acordo com LDB (Lei 9394/96), primeira etapa da Educação Básica, nas últimas décadas, tem recebido mais atenção por parte dos governantes e pesquisadores à medida que vem sendo alvo de diversas políticas públicas educacionais e estudos acadêmicos e científicos. A formação pessoal e profissional do gestor aparece nessa conjuntura como uma ferramenta para enfrentar esses novos desafios que a educação proporciona.

Entre as razões que levam a realização desta pesquisa estão o conhecimento do papel e importância do gestor escolar e a sua contribuição para a promoção de uma 
educação de qualidade para que, com a pesquisa, sejam desveladas as atuais políticas educacionais que efetivamente estão implementadas e seu impacto no desempenho escolar das crianças matriculadas nas creches públicas.

É primordial traçar o perfil do gestor escolar da creche verificando quais Políticas Públicas estão efetivamente implantadas e sua contribuição para a melhoria do desempenho escolar das creches públicas e por fim constatar se o trabalho realizado pelos gestores está em consonância com as ações norteadoras contempladas no Projeto Político Pedagógico das unidades escolares.

É de relevância o presente estudo na medida em que ele poderá, possivelmente, contribuir para apontar sugestões, que venha atender as inúmeras necessidades dos gestores escolares comprometidos com a condução dos aspectos pedagógicos e administrativos da escola sob sua orientação. $E$, na medida em que discutam e reflitam sobre os conteúdos e rumos das políticas educacionais criem estratégias para melhorar a aprendizagem dos alunos, o desempenho dos professores e consequentemente os resultados alcançados pelas unidades de Educação Infantil.

\section{O PAPEL DO GESTOR ESCOLAR NAS CRECHES MUNICIPAIS}

Visto que o gestor é o líder burocrático, pedagógico, administrativo e financeiro, é notório refletir sobre as diversas responsabilidades que lhes são colocadas sobre os ombros e das quais ele não pode se esquivar, tais como: ter conhecimento da legislação que rege os servidores e os recursos públicos, identificar responsabilidades, penalidades e características do processo administrativo, cumprir e fazer cumprir direitos e deveres, valorizar por meio das relações interpessoais todos os servidores, fazer intervenções pedagógicas junto ao professor contribuindo com o processo ensino-aprendizagem, agindo de forma imparcial, ética, sem paternalismo, omissão ou conivência. Tal reflexão conduz a uma auto avaliação e uma nova postura enquanto gestores.

Para compreensão da complexidade do papel do gestor na instituição é válida uma discussão sobre alguns dos desafios que o cargo apresenta. 
No estudo de Botelho (2013, p.50), para formar líderes é necessário que:

[...] no ambiente haja alguém praticando liderança e não apenas gerenciando; ele será o ponto de partida, o estimulador, o incentivador, enfim, o grande mestre. Em segundo lugar, faz-se necessário estudar, ler, conversar, fazer cursos, debater e buscar desenvolver esta competência. Em terceiro lugar, é absolutamente necessário que as empresas revejam os seus esquemas de prioridades no que diz respeito a promoções; em outras palavras, passar a promover aqueles que têm habilidades interpessoais, do que habilidades técnicas.

Assim, o gestor deve ser sensível à demanda dos outros e sempre tomar a iniciativa de ajudá-los para que atinjam seu objetivo. Sendo que, os seus objetivos só serão atingidos existindo a colaboração de todos. Diante disso, é papel do gestor também administrar com responsabilidade as finanças, para tanto é fundamental que ele conheça o percurso das verbas até chegar à instituição. Também é dever do gestor planejar estratégias e as prioridades para a aplicação desses recursos. Portanto acompanhar, assumir, liderar, distinguir, elaborar e criar estratégias para gerir os recursos financeiros da escola são objetivos primordiais que o gestor deve seguir.

Sobre essa questão, Santos (2015, p. 14) reflete que:

Um dilema, até o momento, parece-nos insolúvel: as atribuições previstas nas normas estatutárias e regimentais, embora exijam do gestor escolar maior ênfase no trabalho pedagógico (atividade-fim), acabam dando margem, na prática à predominância do administrativoburocrático ( atividade-meio) por força das tarefas rotineiras; registros de vida escolar do aluno; prontuário dos professores e funcionários, relatórios de medidas e ações propostas pelas secretarias da educação e todo tipo de levantamentos estatísticos. Acresce que para tantas tarefas, regulares ou extras, na grande maioria das escolas públicas, a infraestrutura material, financeira e humana é bastante precária.

É de suma importância a administração dos recursos financeiros e que o mesmo deve ser levado a sério em função do movimento de descentralização, já que esses recursos são importantes para autonomia da escola proporcionando melhores condições do trabalho educativo. Fica constatado que todo dinheiro da escola é necessário que seja prestado contas junto aos órgãos competentes respaldados em 
documentações apropriadas e comprovados pela representação da comunidade escolar.

Para Veiga (2013, p. 99):

A autonomia coloca na escola a responsabilidade de prestar contas do que faz ou deixa de fazer, sem repassar para outro setor essa tarefa e, ao aproximar escola e famílias, é capaz de permitir uma participação realmente efetiva da comunidade, o que caracteriza como uma categoria eminentemente democrática.

Para atuar como gestor de creche pública deve-se ter conhecimentos, competência e habilidades específicas para a elaboração e estruturação do projeto de parcerias, contudo, é importante refletir sobre o alcance que as ações dessa natureza têm, tendo em vista que o objetivo maior é a elevação da qualidade da educação. O gestor no exercício do cargo enfrenta dilemas sobre o que fazer, como e quem irá fazer. São tão somente todos esses questionamentos que são suscitados diante de uma situação de "desamor", "desvalorização" do que é público. Diante de tal dilema a opção é retomar a ideia de humanização do humano no caso do aluno, mas não só dele, também dos funcionários da escola que muitas vezes trata a questão do zelo ao patrimônio com desdém, simplesmente porque é público.

Há dois pontos importantes e de grande relevância: primeiro, a chamada de atenção para o patrimônio imaterial, pois toda instituição de educação não se constitui do material, do físico, de móveis, utensílios valiosos ou não, mas de vida, de doações, de esforços, em fim de histórias. Sejam essas histórias protagonizadas pelos profissionais ou pelos alunos que ali viveram, deixando as suas marcas e levando consigo as construções e os conhecimentos. $\mathrm{E}$ por falar em bens, estes são bens que a traça não corrói, que a ferrugem não consome, mas que se multiplica produzindo vida, através das profissões e profissionais que se espalham na sociedade. Essa é a dimensão da creche e pouco ou nada pensamos nisso. Portanto, educar o corpo docente, discente e demais funcionários para o cuidado com esse patrimônio; assim como do patrimônio material que, também se constituirá no importante cenário que compõe o acervo imaterial e merece igual zelo, uma vez que haverá certamente, o sentimento de pertença àquele ambiente rico em significados. $\mathrm{O}$ segundo ponto é a 
chamada para a falta de valorização do que é público, que consiste também na ausência de identidade com o ambiente, portanto de cidadania.

Por isso é importante que o gestor escolar tenha conhecimento da situação legal do patrimônio imobiliário, pois qualquer situação irregular poderá no futuro se refletir no bom andamento dos trabalhos.

No que diz respeito à gestão dos servidores, o gestor exerce o papel de articulador das ações, capaz de atuar junto a seus pares observando os princípios legais e pedagógicos, dispondo de instrumentos de avaliação de desempenho de todos os servidores periodicamente, se servido dos resultados da avaliação para melhoria da qualidade dos serviços prestados, elaboração de um projeto de formação continuada e qualificação profissional, objetivando o sucesso das aprendizagens dos alunos e a satisfação dos profissionais que atuam na instituição.

De acordo com Chiavenato (2012), liderança é uma função das necessidades existentes em uma determinada situação e consiste em uma relação entre indivíduo e um grupo. A relação entre líderes e subordinados baseia-se em generalizações, como: cada pessoa segue uma luta para satisfazer suas necessidades; as necessidades são individuais; e o relacionamento entre as pessoas é um processo ativo para satisfazer as necessidades. Nesse sentido, o líder é um tomador de decisões ou aquele que ajuda o grupo a tomar decisões adequadas.

Quando os direitos e deveres de cada um, integrando profissionais do magistério e as demais funções são respeitados, tudo funciona em perfeita harmonia. É importante que o gestor conheça a legislação para gerir o quadro de pessoal da escola de forma a dar qualidade nesta prestação de serviço. A formação continuada e a avaliação de desempenho são de grande importância, pois é notório que profissionais bem preparados é fundamental para um trabalho de sucesso. 


\section{INTERAÇÃO: GESTOR COMUNIDADE ESCOLAR}

O gestor escolar deve ultrapassar a visão de educação como treinamento, recuperando para o espaço pedagógico de educação profissional valores como justiça, solidariedade, cooperação, igualdade, respeito às diferenças em oposição à competição e ao mérito individual, ao preconceito, tarefas prioritárias de uma escola democrática, fazendo do mesmo um espaço de diálogo e debate coletivo, é um caminho para resistir às pressões atuais.

Conforme assinala Chiavenato (2012, p. 335-336):

Existem sete dimensões das táticas de poder:

1. Razão: utilização de fatos e dados para elaborar uma apresentação lógica ou racional de ideias.

2. Amabilidade: utilização de elogios, criação de um clima de boa vontade, postura humilde e tentativa de parecer amigável ao fazer um pedido.

3. Coalizão: obtenção de apoio de outras pessoas na organização para uma determinada ideia.

4. Barganha: uso de negociação por meio de troca de benefícios, favores ou vantagens.

5. Afirmação: utilização de uma abordagem direta e vigorosa, lembretes repetidos, ordens para cumprimento ou citação de regras que exigem obediência.

6. Autoridades superiores: obtenção de apoio dos níveis mais alto da organização para a ideia.

7. Sanções: utilização de recompensas e punições, como promessas ou ameaças em relação a salários, avaliação do desempenho ou promoções.

Antes de qualquer coisa, o gestor precisa romper velhos paradigmas e construir uma nova identidade para a escola, pois há um costume ou até vício, dos servidores que atuam nas escolas públicas, delas fazerem a extensão das suas casas; principalmente nas Unidades de Educação Infantil, talvez seja pelo fato da sua origem está pautada 
mais no cuidar, no assistencialismo do que no educar; mas ocorre é que, na maioria das vezes é a repartição pública "escola" que está tendo que se adequar ao funcionário, que se sente à vontade para descumprir as regras de funcionamento. Então, diante do confronto entre a gestão dos servidores e desta realidade, brevemente apresentada, entende-se que seja mais que necessário desenvolver nas escolas políticas de gestão dos servidores. Entretanto atuar nesta perspectiva exige da equipe gestora conhecimentos, amadurecimento administrativo e pedagógico; pois gestão democrática tem sido confundida com paternalismo, omissão falta de atitude frente ao não cumprimento de compromissos.

Assevera Alvarez (2014, p.73):

O regimento escolar possui estrutura própria, composta por elementos tais como: introdução; artigos que regulam o funcionamento dos elementos da estrutura; artigos relativos à convivência; artigos que incluem a previsão de soluções imediatas perante situações de contingência; artigos que estabelecem as condições de modificação do próprio regulamento.

Contudo é preciso reforçar a necessidade de investir no crescimento, na qualificação primeiro pessoal dos indivíduos que fazem parte deste importante grupo social que é a escola; depois no seu aprimoramento profissional. É importante instaurar outro olhar sobre a composição escolar, que precisa ser levada a sério e deve ser percebida à luz da legalidade para os cargos e funções, ou seja, por mais familiar que pareça, a escola é uma empresa, uma instituição. É preciso desvendar os olhos e primar por uma gestão cujas bases administrativas estejam bem definidas e estruturadas em estatutos e planos de carreira; reconhecendo sim, que aquela composição é feita por pessoas que merecem e precisam ser respeitadas em seus direitos, mas que para isso necessitam conhecê-los, bem como os seus deveres.

Na gestão democrática deve haver compreensão da administração escolar como atividade meio e reunião de esforços coletivos para o implemento dos fins da educação, assim como a compreensão e aceitação do princípio de que a educação é um processo de emancipação humana; que o Plano Político pedagógico (P.P.P.) deve ser elaborado através de construção coletiva e que além da formação 
deve haver o fortalecimento do Conselho Escolar. (PARANÁ, 2012, p. 25)

A política de formação continuada em serviço é salutar nesta construção pessoal e profissional, onde todos participem conjuntamente do conhecimento das funções e importâncias de cada profissional dentro da escola, onde cada setor possa partilhar as suas dúvidas, angústias e dificuldades e cada servidor possa auto avaliar-se e avaliar o outro, com a finalidade única de confirmar os acertos e rever as falhas. Para isso é preciso desenvolver a "cultura da escuta".

É conveniente lembrar que a avaliação institucional é uma ferramenta indispensável para o planejamento, a gestão e demais atividades que constituem o currículo da creche, tendo uma visão crítica, porém, compreensiva, com objetivos e metodologias definidas de forma democrática, com processos e instrumentos rigorosos e consistentes dos pontos de vista teórico, técnico e político, abrangendo mais que a produção e a qualidade do trabalho das pessoas e também a própria instituição. Em suma, é um procedimento de detecção de pontos positivos e negativos, permitindo delinear ações, individuais e coletivas, de aprimoramento institucional.

A formação do professor e seu nível de participação nas decisões políticas da educação assumem papel relevante no processo do projeto pedagógico, tanto nas suas dimensões pedagógicas específicas, quanto em sua dimensão política, enquanto cidadãos críticos e conscientes de seu papel social. Consequentemente, a deficiente competência profissional em qualquer etapa, afetará as demais. Por outro lado, qualquer reflexão sobre a formação do professor, apontará as discussões políticaspedagógico sobre a sociedade que se pretende o que se entende por cidadania, o papel social neste contexto, os tipos de vinculação existentes entre as demais políticas públicas.

Somente mantendo a organização e a participação de todos os envolvidos no processo educacional, conseguiremos impor a vontade do grupo e assegurar os princípios articulando uma gestão pedagógica obtendo pontos positivos no desempenho escolar interno e externo. 
A efetivação da gestão democrática e participativa está intimamente ligada a postura e concepções do gestor escolar, que pode contribuir ou atrapalhar a implantação de processos participativos. A comunidade escolar ainda não se apropriou da escola pública que ainda é vista como propriedade do governo ou do pessoal da escola, privilegiando os segmentos docentes e administrativos. Todos os segmentos da comunidade podem e devem participar da gestão desde que se estabeleça critérios bem definidos para orientar e definir esta participação.

A Lei 9394/96, articula que apesar das dificuldades decorrentes da implantação e funcionamento dos colegiados escolares, estes são um mecanismo capaz de promover o despojamento da dominação de uma só pessoa, superando a monocracia como lógica de funcionamento da direção escolar.

Para que a gestão democrática se efetive nas creches assim como nas demais escolas públicas é necessário incluir os sujeitos na unidade de ensino na elaboração de suas ações e conscientizar toda comunidade escolar, a respeito do que é e como se faz gestão democrática.

\section{CONSIDERAÇÕES FINAIS}

As reflexões apresentadas durante este trabalho sinalizaram a importância de estabelecer o clima de satisfação, participação e integração de toda comunidade escolar, para adquirir resultados positivos aos preceitos legais e pedagógicos no ambiente escolar.

Ser um gestor escolar significa ter o aluno como personagem central do trabalho. Conhecer, pesquisar, vivenciar e dispor de um leque de propostas que sejam adequadas as necessidades, aos interesses, às habilidades e as dificuldades dos alunos, pais e profissionais da escola. É imprescindível atualização constante quanto as teorias, as pesquisas e aos debates relativos à educação escolar, assim, como as políticas públicas, aprimorar conhecimentos e ampliar a consciência com relação à necessidade de cada envolvido, torna-se necessário para o desenvolvimento da aprendizagem dos alunos. 
Diante do exposto espera-se que o gestor escolar ultrapasse a visão de educação como treinamento, recuperando para o espaço pedagógico valores como justiça, solidariedade, cooperação, igualdade, respeito às diferenças em oposição à competição e ao mérito individual, ao preconceito, tarefas prioritárias de uma escola democrática. Fazendo do mesmo um espaço de diálogo e debate coletivo, é um caminho para resistir às pressões atuais

Enfim, é válido considerar que a partir do momento que a gestão começa a delegar responsabilidades, nas várias etapas da organização da unidade de ensino, cabendoIhe estabelecer diretrizes gerais, resultantes da ampla discussão com o pessoal de apoio e com as equipes técnico-docentes. Esse diálogo refletirá sempre o Projeto Político Pedagógico que a unidade de ensino quer implantar e desenvolver, facilitando a articulação necessária com as Políticas Públicas educacionais vigentes.

\section{REFERÊNCIAS}

ALMEIDA NETO, H de. Construção do conhecimento científico. Canoas: Universidade Luterana do Brasil, Pró-reitoria de Pesquisa e Pós-Graduação. Próreitoria de Ensino a Distância, 2008. 162 p.

ALVAREZ, M. A. (org.) O projeto educativo da escola. Tradução de Daniel Ángel Etcheverry Burgunõ. Porto Alegre, Brasil: Artmed, 2014.

ANDREW, R. Segredos da Liderança. 3. ed. Rio de Janeiro, Brasil: Jorge Zahar, 2012.

BOTELHO, E. F. Do gerente ao líder: a evolução do profissional. 5. ed. São Paulo, Brasil: Atlas, 2013.

BRASIL, Ministério da Educação e do Desporto. Lei 9394/96 - Lei de Diretrizes e Bases da Educação Nacional. Brasília: A Secretaria, 1996.

CHIAVENATO, I. Comportamento organizacional: a dinâmica do sucesso das organizações. 4. ed. São Paulo, Brasil: Pioneira Thomson Learning, 2012. 
PARANÁ. (2012). Projeto Político Pedagógico do Colégio Estadual Professor Amarílio. Guarapuava, Brasil. Disponível em: www.grpamarilio.gmail.com. Acesso: 20/06/2018.

SANTOS. M. O. V. dos. A identidade da profissional de Educação Infantil. In. Perspectiva para a educação infantil. Araraquara, Brasil: Junqueira \& Marin., 2015.

Subsídios para Diretrizes Curriculares Nacionais para a Educação Básica Diretrizes Curriculares Nacionais Específicas para a Educação Infantil. DCOCEB/SEB/MEChttp://www.amavi.org.br/sistemas/pagina/setores/educacao/freia vi/arquivos/Subsidios_RCENEI.pdf

VEIGA, I. P. A. Escola: espaço do projeto político pedagógico. Campinas, Brasil: Papirus, 2013.

Enviado: Julho, 2020.

Aprovado: Setembro, 2020. 